\title{
Research on the Teaching Methods of English Idiom Chunks in College English
}

\author{
Liuchun Wen*
}

\author{
Guangdong Technical College of Water Resources and Electric Engineering \\ *Corresponding author. Email: wenliuchun@126.com
}

\begin{abstract}
There are a great number of English idioms in College English teaching. An English idiom can be viewed as a chunk with a fixed meaning instead of a simple combination of literal meanings of several single words. It is not easy for Chinese students to learn English idioms. For Chinese college students, English idiom chunks acquisition can be influenced by four factors. In order to teach English idiom chunks more effectively, College English teachers can adopt five good teaching methods: the thematic approach, the situational approach, the source method, the EnglishChinese contrast method and the paraphrasing method.
\end{abstract}

Keywords: The teaching methods, English idiom chunks, Figurative meaning, College English.

\section{INTRODUCTION}

Since the 1980s, people have begun to pay attention to the study of English idioms acquisition. Most research mainly focus on the transfer of mother tongue, idiom processing strategies, avoidance phenomena, context effects and idiom teaching. Irujo (1984, 1986, 1993) divided English idioms into three categories by studying the similarity between Spanish idioms and English idioms: equivalent idioms, similar idioms and different idioms. It is found that the more similar the mother tongue and the target language, the more beneficial it is to promote the positive transfer of the mother tongue. At the same time, it is also found that the level of English proficiency has a certain impact on the understanding of English idioms. The higher the English proficiency of the learner is, the more possibility of using the target language strategy there is, and the lower the English proficiency of the learner is, the more possibility of using the native language strategy. Laufer (2000) divided the similarities of the first language (L1) and the second language (L2) into four levels from the three dimensions of concept, form and distribution and compared them. The four levels are: L1-L2 completely equivalent idioms, L1-L2 partial equivalents idioms, different idioms in L1-L2, and idioms in L1 idioms which are absent in L2. Laufer found that idiom avoidance is related to the similarity of L1-L2 idioms. For the impact of the difference in the degree of similarity between L1-L2 idioms on learners' avoidance strategies, it is found that the idioms are avoided the most with equivalent semantics and forms in L1 and L2, as well as the idioms with either semantics or forms which are absent in L1-L2. In a survey of 78 French native students, Frank Boers \& Murielle Demecheleer (2001) tested their understanding of the meaning of unfamiliar English idioms without contextual clues. It is found that second language learners will be affected by the cultural differences between their mother tongue and the second language when they understand idioms; and learners rely more on context to understand low-transparency idioms, and use semantic decomposition strategies to understand hightransparency idioms. Tang Ling (2009) investigated the influence of language proficiency and idiom types on the use of Chinese college students' English idiom comprehension strategies. The experimental results show that the subjects adopted 12 strategies in the process of idiom comprehension. Among them, the most used strategy is the strategy of guessing based on context; the least used strategy is the strategy of guessing based on image. At the same time, language proficiency has a significant impact on the use of idiom comprehension strategies. Higher-level learners use more and more effective idiom comprehension strategies than middle-level learners. Intermediate level learners pay more attention to the analysis of idiom language form and literal semantics; while advanced learners are better at guessing the meaning of idioms by using context, relevant knowledge of their mother 
tongue and the connection between the literal meaning of idioms and its metaphorical meaning. Wu Xudong (2006) believes that conceptual basis or cultural connotation has an impact on idiom comprehension: idioms with the same conceptual basis or cultural connotation and the same or similar language expression are the easiest to understand; Idioms with completely different conceptual basis or cultural connotation and the same or different language expression in the L1 and the $\mathrm{L} 2$ are the most difficult to understand; The degree of difficulty of understanding idioms with the same conceptual basis or cultural connotation and different language expressions in L1 and L2 are between the above two cases. Mei Ye (2010) believes that the teaching of English idioms is an effective way to achieve the purpose of college English teaching, and proposed several teaching methods, such as thematic method, situational method, classification method, source method and translation method.

\section{THE DIFFICULTIES OF ENGLISH IDIOMS CHUNKS ACQUISITION}

Since Chinese and English belong to different language systems, it is not easy for Chinese students to learn English, especially English idioms. English idioms can be viewed as chunks. For Chinese college students, English idiom chunks acquisition can be influenced by the following four factors.

\subsection{The Impact of Negative Transfer of Mother Tongue}

The concept of mother tongue transfer was proposed in the comparative analysis theory that emerged in the 1940 s and 1950s. In the process of second language acquisition, the habits of the learner's use of L1 will directly affect the second language acquisition, playing a positive or a negative role. The positive influence on the L2 acquisition resulting from the similar components between L1 and L2 is called positive transfer, and the negative influence on the L2 acquisition resulting from different components are called negative transfer. In the process of acquiring English idioms, it is inevitable that it will be affected by the negative transfer of the mother tongue and cause difficulties. For example, when Chinese learners read the English idiom pull one's leg, they will mistake it for its literal meaning of "exert force on one's leg by taking hold of it ", because they comprehend the meaning of this idiom in a literal sense. As a matter of fact, the real meaning of pull one's leg is "make a joke on someone". We can study a second example. The idiom chunk eat one's words is often mistaken by second language learners as the meaning of "breaking one's words", which is conveyed by another idiom chunk lose one's words, but in fact it means "admitting one's mistakes". The mistakes have all resulted from the negative influence of the mother tongue or the L1 on L2, because learners take for granted that these English idioms as L2 correspond to certain expressions in the L1. In fact, there are many differences between Chinese and English in terms of expression, thoughts, and pragmatics. For Chinese learners, it is necessary to carefully distinguish the differences between Chinese and English and try to understand English idioms with the thinking mode of English speakers.

\subsection{The Influence of the Environment of Second Language Learners' English Idiom Chunks Acquisition}

One of the main reasons why English idiom chunks are difficult to learn is that there is no good learning environment. With the development of the economy, Chinese people pay more and more attention to the learning of English, but most Chinese English learners attach little importance to English idiom chunks acquisition. In fact, English idioms are the essence of the English language. For native English speakers, their daily language is full of various English idioms. Therefore, a good command of English involves a master of a great amount of English idiom chunks. However, the English language learning environment of Chinese learners is not conducive to their mastering of English idioms. There are mainly three factors.

First, the importance of English idiom chunks acquisition is not highlighted in the English textbooks, many of which exclude some corresponding idiom teaching modules. In some textbooks, English idioms are simply listed as "special or other expressions" in the vocabulary list at the back of the text without additional explanation, which cannot attract the attention of teachers and learners.

Second, English idiom chunks acquisition is not listed in the syllabus, which determines the teacher's attitude towards English idiom chunks-paying little attention. English learners acquire English mainly from the classroom, where the teacher teaches English. The syllabus is like the driver's navigator, which directs the teacher's teaching. Without English idiom chunks listed in the syllabus, the teacher pays little attention to English idioms chunks teaching, which make their students weak in English idiom chunks.

Third, most English learners learn "dumb" English, which means they rarely communicate with each other in English, leading to a restricted use of English idiom chunks.

Fourth, English learners don't pay enough attention to English idiom chunks. When coming across English idiom chunks, English learners simply find out their meaning without trying to explore their deep meaning. On the other hand, native English speakers tend to use simple, easy-to-understand vocabulary when speaking 
to second language learners, avoiding using idiom chunks.

\subsection{The Impact of Cultural Differences}

Idioms are the carrier of a nation's language and culture, containing rich cultural connotations. Due to the great differences between Chinese and Western cultures, learners will inevitably be influenced by culture when learning English idioms. When learning some culturalrelated idioms, learners will be confused and feel at a loss.

Many English idioms come from ancient Greek mythology, "Bible" allusions and Aesop's fables. For example, the idiom under the rose comes from Roman mythology. Cupid, the little love god in Roman mythology, is the son of the god Mars and Venus, who are the Aphrodite in Greek mythology. It is said that Venus was born out of the foam of the sea and is known for her beauty, by which Gods from Zeus to Olympus are all overwhelmed. There are many love legends about her. In order to protect the reputation of his mother, the little love god Cupid sent a bouquet of roses to the silent god Habercrates, asking him to keep his mouth shut, without broadcasting the love affairs of Venus to the Universe. After receiving the rose, Hubercrates remained silent and became a veritable "God of Silence." Therefore, the ancient Romans regarded roses as a symbol of silence or keeping secrets. God of Silence acquires the meaning of "secretly, secretly", becoming a fixed English idiom chunk. There are some related English expressions, such as born under the rose which means "illegal, illegitimate" and do under the rose which means "secretly".

The idiom Apple of Sodom is derived from the "Old Testament Genesis". Sodom is a city in ancient times, located near the present Dead Sea. It is said that the city is the abyss of evil. In this city, there are some very tall apple trees with very beautiful fruits. People who passed there couldn't help but pick one and taste it, but when it was peeled in their hands, it was disappointing. Inside, there was a mass of ashes-like things that couldn't be eaten at all. Later, Apple of Sodom is used to express the meaning of "seemingly valuable things which are not worth a damn". These idioms are closely related to the culture. Without understanding the culture of Englishspeaking countries, Learners cannot learn English idioms well.

\section{TEACHING METHODS OF ENGLISH IDIOM CHUNKS}

In order to teach English idiom chunks more effectively, teachers can adopt some good teaching methods

\subsection{Thematic Approach}

Thematic approach means that the teacher summarizes English idioms based on the topics of each unit and explains them to students. If this unit is based on a certain character, the teacher can find out some frequently used fixed expressions with a person's name, such as Tom and Jerry(sweet drink mixed with eggs, hot water and rum), Tom, Dick and Harry(Zhang San Li Si, ordinary people), Old Tom(strong gin), John Hancock (signature), Jane(ordinary woman), Lazy Susan (turntable dining table), rob Peter to pay Paul (demolish the east wall in order to mend the west wall), etc. Besides, the teachers should require students to take notes and classify relevant English idiom chunks according to the topic method. Hence, besides the knowledge of English idiom chunks, the teacher taught the method of learning, following which students learn by themselves after class.

\subsection{The Situational Approach}

Situational approach refers to learning English idioms in a certain situation. Teachers should not only improve students' reading and writing skills, but also strengthen learners' listening and speaking skills. At present, many English textbooks adopt materials such as conversations and reports in real contexts, which are filled with abundant English idioms. Therefore, first, the teacher can ask their students find out or write down those unfamiliar idioms, after that, the teacher asks the students guess their meanings according to the situation, and finally, the teacher tells the correct explanation of those idioms. For example, when discussing the topic of family, the teacher can introduce the proverb East or west, home is best. So I love my family very much. which means "Golden nests and silver nests are not as good as their own kennels." The teacher can begin his talking about the topic of children with the question "Who is the only child in your family? Are you the apple of their parents?" followed by asking the students to guess the meaning of this sentence and offer an answer. Students can easily decompose the meaning of this sentence: "Which one of you is the only child? Are you the jewel of your parents?" Therefore, it is easier for students to understand and use English idioms in the context.

\subsection{The Source Method}

The source method means understanding the ins and outs of English idioms, which is conducive to the deep understanding of English idiom chunks, which are the carrier of national culture. Understanding the origins of English idioms, such as history, culture, religious beliefs, customs, values, geographical environment, etc., is beneficial to a better understanding and mastery of English idiom chunks. For example, the English idiom 
"the Troian horse" literally means "Trojan horse", which comes from Homer's epic poem "Odyssey". The Greeks and the Trojans had been fighting for 10 years, and neither won the victory. Finally, the famous Greek hero Odysseus came up with the trick of a wooden horse, making a giant horse out of wood and placing it outside Troy. All the Greek soldiers pretended to retreat and hide in the nearby bay by boat, while Odysseus led 20 warriors into the horse belly beforehand. The Trojans mistakenly believed that the Greeks had already retreated. They opened the city gates and saw the huge wooden horse outside the city. They thought it was a gift from the Greeks worshipping the gods. In the middle of the night, while the Trojans were dreaming and unsuspecting, the Greek heroes hiding in the Trojan crawled out, opened the city gate, and sent a signal to meet with the Greek army hiding in the nearby bay and destroy the Troy City in one swoop. When knowing the origin of this idiom, learners will be more impressed with the idiom and easily remember this idiom.

\subsection{The English-Chinese Contrast Method}

The English-Chinese contrast method refers to learning English idioms based on the similarities and differences between English and Chinese. There are many differences between the English and Chinese languages, but there are some similarities. Teachers can adopt English-Chinese contrast when explaining the meaning of English idioms. Based on the similarities and differences between L1 (Chinese) and L2 (English), the teacher teaches students English idioms with the method of comparative analysis, which will help students understand English idioms correctly. Some English idioms have the same meaning as Chinese idioms or phrases. For example, strike while the iron is hot can be directly borrowed from the Chinese expression Chenre-datie. Some English idioms have the same meaning as Chinese idioms or phrases but have different metaphors. For example, like a cat on the hot brickes has the same meaning as xiang reguo shang de mayi in Chinese, but has different metaphors: in English "cat" is used, while in Chinese "ant" is used. Some English idioms have different meanings and metaphors from Chinese idioms or phrases. For example, instead of "child play", child's play expresses "very easy things to do". This kind of completely unequal idioms between English and Chinese is more difficult. Teachers can teach students to learn in context, for example, Driving a car isn't child's play even when you've had practice, which means "Even if you have practical experience, driving a car is not easy".

\subsection{The Paraphrasing Method}

The Paraphrasing method means that the teacher offers an article containing many idioms and explains the meaning and usage of these idioms found out by students, and then, the teacher asks the students to retell or adapt the content with the help of idiom chunks. For example, At Lincoln High School, basketball was a hot topic. The school team, the Lions, was usually one of the best in the city. This year, though, something was wrong. The Lions were blowing hot and cold. They'd win a game and then lose two or three. For the first time in thirty years, they were in danger of missing the playoffs. Coach Bud Walker was really in the hot seat. This was his final year at Lincoln High School, and he didn't want to be remembered as a losing coach. The thought made his blood run cold. The italics words in this passage are all idioms, hot topic means "hot topic", and blowing hot and cold means "volatile" , In the hot seat means "uncomfortable or embarrassing situation", made his blood run cold means "to make someone feel creepy".

\section{CONCLUSION}

An idiom is a form of figurative language that can usually have both a literal and a figurative meaning, depending on the context. There are a great number of English idioms in College English teaching. English idioms need to be comprehended from the perspective of figurative meaning instead of literal meaning. Therefore, an English idiom can be viewed as a chunk with a fixed meaning instead of a simple combination of literal meanings of several single words.

It is not easy for Chinese students to learn English idioms. For Chinese college students, the difficulties of English idiom chunks acquisition can be influenced by four factors. In order to teach English idiom chunks more effectively, College English teachers can adopt five good teaching methods.

\section{ACKNOWLEDGMENTS}

The study is funded by 2021 Education and Teaching Innovative Research Program in Guangdong Technical College of Water Resources and Electric Engineering: The Study of the Model of Vocabulary Teaching in College English Based on the Theory of Lexical Chunks (GX0205JGXM007).

\section{REFERENCES}

[1] Altenberg, B. \& Granger, S. The grammatical and lexical patterning of "make" in native and nonnative student writing [J]. Applied Linguistics, 2001(2): 173-194.

[2] Conklin, K. \&N. Schmitt. Formulaic sequences: Are they processed more quickly than nonformulaic language by native and nonnative speakers? [J]. Applied Linguistics, 2008, 29 (1):7290. 
[3] Lewis, M. The Lexical Approach: the State of ELT and a Way Forward [M]. England: Language Teaching Publications, 1993.

[4] Zhang Hui, Yiming Yang and Jiexin Gu, Feng Ji. 2013. "ERP correlates of compositionality in Chinese idiom comprehension". Journal of Neurolinguistics 26: 89-112.

[5] Sandrine Le Sourn-Bissaoui, Stéphanie Caillies, Stéphane Bernard, Michel Deleau, \& Lauriane
Brulé. Children's understanding of ambiguous idioms and conversational perspective-taking. Journal of Experimental Child Psychology 2012(112): 437-451.

[6] Irujo, S. 1986. "Don't put your leg in your mouth: Transfer in the acquisition of idioms in a second language.” TESOL Quarterly 20, 2: 287-304. 